\title{
Benchmarking strategic alignment of business and IT strategies: opportunities, risks, challenges and solutions
}

\author{
Modupeola Dairo $^{1} \cdot$ Josephine Adekola $^{2}$ Charalampos Apostolopoulos ${ }^{1} \cdot$ \\ Georgios Tsaramirsis ${ }^{3}$ (i)
}

Received: 8 March 2021 / Accepted: 29 September 2021/Published online: 8 October 2021

(C) Bharati Vidyapeeth's Institute of Computer Applications and Management 2021

\begin{abstract}
Business and IT strategy alignment is a complex dynamic process in which organizations are in a position to enable extensive IT capabilities to achieve their business objectives. This interdependence is amplified by the COVID-19 crisis, which makes the integration of IT and business strategies more important than ever. This paper mainly aims to contribute to the understanding of strategic alignment from a practical perspective, as well as to demonstrate the applicability and robustness of the Strategic Alignment Model (SAM). Moreover, potential opportunities and risks associated with the strategic alignment of business and IT strategies are analysed. Findings are discussed after a qualitative analysis of 31 participants (semi-structured survey and interviews). Results indicated several difficulties affecting the strategic alignment implementation transcend the business and IT strategies like communication, corporate culture, governance, resource prioritization, and effective leadership. The study
\end{abstract}

Georgios Tsaramirsis

gtsaramirsis@hct.ac.ae

Modupeola Dairo

mkdairo@googlemail.com

Josephine Adekola

Josephine.adekola@gcu.ac.uk

Charalampos Apostolopoulos

charalampos.apostolopoulos@strath.ac.uk

1 Department of Management Science, University of Strathclyde Business School, Scotland G4 0QU, UK

2 Department of Finance, Accounting and Risk, Glasgow School of Business and Society, Glasgow Caledonian University, Glasgow G4 0BA, Scotland, UK

3 Higher Colleges of Technology, Abu Dhabi Womens's College, Abu Dhabi, United Arab Emirates contends that there is a need to align and harmonize different agendas and interests within an organization and improve the understanding of the value of Strategic Alignment.

Keywords Strategic alignment · Business strategy $\cdot$ IT strategy $\cdot$ Strategic Alignment Model (SAM)

\section{Introduction}

The importance of strategic alignment of business and IT strategies has previously been recognized $[1,2]$ but has taken on a new level of significance due to the current global coronavirus crisis and the various government responses including, lockdown restrictions and closure of business premises. Therefore, organizations of all sizes have had to re-examine how they operate [3], and this has seen an increase in remote working, digital interaction between stakeholders, or harnessing of emerging technologies to innovate and improve performance. Whatever the new normal may emerge following the coronavirus responses, it is essential that organizations carefully consider the opportunities and risks associated with aligning business and information technology (I.T.) strategies [4-7] and the new technologies brought to the scenes during the fourth industrial revolution. [8-11].

The concept of strategic alignment was first introduced by Henderson \& Venkatraman [12] as "the degree of fit and integration among business strategy, IT strategy, business infrastructure, and IT infrastructure". Luftman [13] defined a "good strategic alignment" as the application of the appropriate information technology at the right time and place with the purpose of helping organizations to achieve their corporate goals and objectives. McKeen and 
Smith [14] further define it as 'when an organization's goals and activities and the information systems that support them remain in harmony.'

Despite the significant attention and interest that strategic alignment has received from industrialists, consultants, and academics, the concept is still in its infancy and appears to lack a theoretical foundation and practical validation [13-15]. The aim of this paper is to contribute to the understanding of strategic alignment from a practical perspective as well as to demonstrate the applicability and robustness of the Strategic Alignment Model (SAM). The opportunities, risks, challenges, and solutions associated with the strategic alignment of business and IT strategies are also discussed in this paper.

\section{Strategic alignment-emerging trends and debates}

Traditionally, business and I.T. strategies were seen as two distinct business operations and I.T. departments have often performed tasks as requested by the business managers and customers' demands. However, due to advances in the field of information and communication technology (ICT), coupled with a better understanding of the value of the business and I.T. strategic alignment, there is a shifting culture and paradigm in how the relationship between the two are viewed, with scholars and practitioners arguing for better integration and harmony of business and I.T. functions and strategies [16-19].

There are many arguments for or against strategic alignment of business and IT strategies, see for example, [16-19]. Some scholars have argued against strategic alignment from the perspective that alignment research is mechanistic and could not be realistically implemented in an increasingly dynamic business environment, albeit this criticism is disproven by the concepts or arguments of the Dynamic Capabilities Framework (DCF) and the Co-evolutionary framework. DCF as proposed by [20] stated that for businesses to successfully address the constant changes in the business environment, they need to "integrate, build, and reconfigure internal and external competencies". DCF considers alignment as a way through which corporate entities maintain strategic flexibility, which enables them promptly and appropriately to respond to the changes in the business environment [21].

The Co-evolutionary perspective coordinates the alignment of business and information technology strategies through continuous adjustment and learning [22]. This perspective is viewed as a "joint outcome" of the work of managerial decisions and various elements of the organization, which includes information technology [23]. Secondly, in cases where the business strategy is not known or is in process, attaining strategic alignment is difficult. Thirdly, alignment is not to be considered as an end goal, since the business must evolve consistently in response to the environment. Lastly, businesses should often be challenged by information technology, and not be led by information technology [24].

There are various approaches or models of strategic alignment that have been developed as a means of framing the alignment of business and information technology. These include business strategy versus information technology strategy, organizational infrastructure versus IT infrastructure, IT governance [1], and alignment mechanisms. These have been used in different contexts, including surveying IT and business executives, small business units (SBU's), manufacturing firms and academic institutions such as the research by the following authors $[8,9]$. However, the lack of a universally accepted model or framework on the assessment of strategic business and IT alignment means that many organizations have been unable or at least struggle to understand how to define, identify, measure, and implement strategic alignment of business and IT strategies. One model that has received recognition in the field of strategic alignment is the strategic alignment model (SAM). SAM was proposed in [10] in the 1980s and has been recognized within the literature as a key strategic alignment framework [11] based on its use in different contexts including surveying IT, business executives, small business units (SBU's), manufacturing organizations and academic institutions.

SAM, as shown in Fig. 1, categorizes strategic alignment into four major domains, which include "business strategy", "information technology strategy", "organization infrastructure and processes", and "IT infrastructure and processes". The 'business' and 'information technology' strategies are recognized as external components whereby 'organizational infrastructure' and 'information

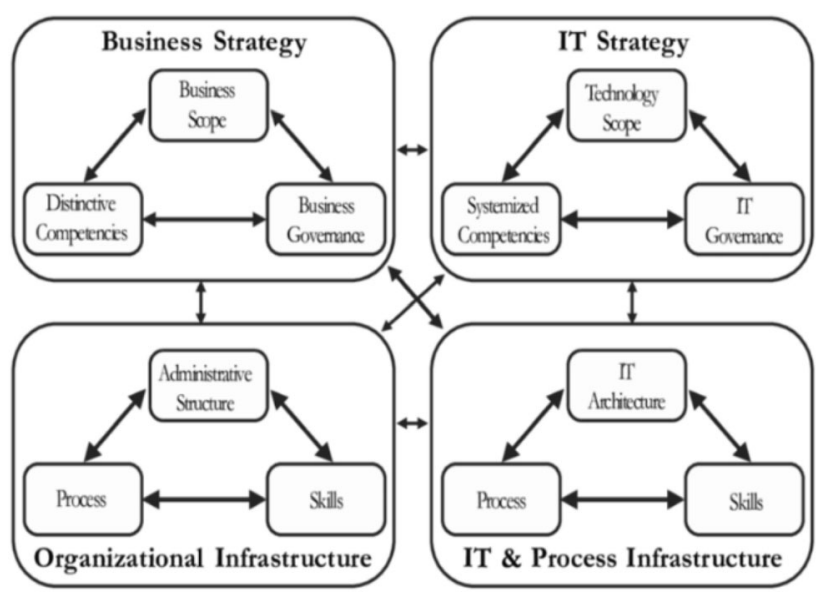

Fig. 1 The strategic alignment model [10] 
technology infrastructure and processes' are considered internal components. The business strategy is the organizations' tactics to be employed to succeed in the market. This includes processes, people, and resources. Information technology strategy is the second domain within the external component, which encompasses the tools, processes, or thinking that makes information technology work alongside the business strategy to achieve organizational goals. Strategy organization infrastructure and processes deal with organizational structure and the makeup of the firm including leadership, communication style, decision-making processes. IT infrastructure and processes comprise the use of the technology infrastructure (hardware, software and people) needed to effectively execute the organization's IT strategy in line with the organization's general goals.

At the strategic level, the SAM covers alignment between information technology and business level strategies and is therefore considered a driver, but at the operational level, it is considered an enabler when covering the alignment of business processes and organization, and IT infrastructure and organization. Studies have shown that SAM can successfully predict IT and business alignment with a high degree of accuracy, while it is also tested empirically $[12,13]$. SAM is both theoretically and practically viable in measuring information technology and business alignment as well as measuring its effect on organizational performance. Nevertheless, one fundamental limitation of SAM is that it fails to explain the 'how' and the specific processes which are involved in achieving strategic alignment of IT and business strategies. Having stated this, one fundamental gap of SAM as identified in the literature is the failure of the model to explain the 'how' and the processes involved in achieving strategic alignment of IT and business strategies. This paper aims to make a theoretical contribution in the understanding of the 'how' process of strategic alignment, including challenges and solutions associated with implementing strategic alignment of business and IT strategies. The next session set out the study methodology and the data collection process.

\section{Opportunities and risks associated with the strategic alignment of business and IT strategies}

Strategic alignment of IT and business brings many advantages, including enhanced operational efficiencies, business innovativeness, and additional competitive advantage, which together lead to improved performance [14-16]. Organizations that have been able to align business strategy and information technology successfully have created very significant business returns and made quality improvements [17]. They have also added value to the effectiveness of organizations by acting as agents of change that are focused on business imperatives and helping to achieve effectiveness and efficiency, costs reduction, creating barriers to entry, improving customer and buyer/supplier relationships, and creating new products and business solutions.

Nevertheless, the ability to achieve and maintain this harmony can be challenging because strategic alignment addresses both effectiveness (doing the right things) and efficiency (doing things right). Researchers in [1] explain that the complexity of alignment is akin to building a bridge between two constantly moving shores, with business on one hand and information technology on the other hand. Measuring the alignment "as is" can form the foundation for an informed decision-making process for desired scenarios in terms of problem identification and pinpointing opportunities that need to be addressed and exploited respectively to improve strategic business and information technology alignment. Alignment can result in pathologies that would need to be carefully managed if organizations want to avoid undesired business and IT costs and to maximize the benefit of achieving the strategic purpose [20]. Table 1 reflects on the opportunities and risks associated with strategic alignment of business and IT strategy, as adapted from the literature.

\section{Methodology}

This paper adopts the epistemological method with a specific focus on interpretivism because it allows an overall better understanding of the strategic alignment from a practical perspective while drawing on the experiences of respondents under qualitative analysis. Authors in [21] argue that "interpretivism is necessary for the researcher to understand differences between humans in our role as social actors".

The data collected in this paper was sourced from direct interviews with three members of the senior management of DXC technologies. An in-depth one-to-one semi-structured interview was carried out to gain a deeper understanding of the aim and objectives of this. In addition to the three interviews, data was collected from 28 employees through a semi-structured survey. In total, data was collected from 31 employees at DXC technology with experience spanning between three to 30 years at DXC Technology. Secondly, to ensure the data's validity and to reduce bias in analysis, the data from the interview was recorded. The interview design and questions focus on the following: Understanding and benefits of strategic alignment, the changing strategic alignment landscape following 
Table 1 Opportunities and risk associated with strategic alignment in contemporary society

\begin{tabular}{lc}
\hline Opportunities & Risks \\
\hline $\begin{array}{l}\text { SA can eliminate redundancies and waste thereby } \\
\text { enhancing organizational profitability [25] }\end{array}$ & $\begin{array}{c}\text { SA can make the business vulnerable to the consequences of the current dynamic } \\
\text { business environment [25] }\end{array}$ \\
$\begin{array}{l}\text { SA can lead to the general improvement of business } \\
\text { performance [26] }\end{array}$ & $\begin{array}{c}\text { SA can make organisations incur losses when implemented with an unclear } \\
\text { strategy [2] }\end{array}$ \\
$\begin{array}{l}\text { SA brings competitive advantage needed to survive in a } \\
\text { complex business environment [27] }\end{array}$ & $\begin{array}{c}\text { SA could be difficult to understand and can work against the firm in that case [1] } \\
\begin{array}{l}\text { SA ensures the synchronization of business processes } \\
\text { which leads to an organization's efficiency [28] }\end{array}\end{array} \quad \begin{array}{c}\text { IT strategy is likely to be the primary driver of a business, thus making the actual } \\
\text { business strategy suffer. Considering that IT is insensitive to market changes, the } \\
\text { business may suffer in the long run [29] }\end{array}$ \\
\end{tabular}

the coronavirus pandemic, description of the process of strategic alignment (Business \& IT strategy), challenges, barriers and recommendations. The responses were coded with unique identifiers for anonymity and securely stored to restrict access. The next section of this paper discusses the associated findings and analysis.

\section{Findings and analysis}

The main aim of the analysis is to engage the thematic analysis framework in its analysis. Therefore, to address this paper's objectives accordingly, it is sub-divided into three sub-sections: The understanding of SA from the employees' perspective; the challenges of implementing alignment; and the value of SAM from a practical perspective.

\subsection{The understanding of strategic alignment}

Participants were asked to define strategic alignment. Participants define SA as forward 'think approach', brings 'harmony across levels' and 'linking strategy and processes.'

"The process whereby an organisation is forward thinking in its approach to trading and dealing with the market. This includes setting out a goal/business objective, mapping out a process and aligning the organisation culture, structure and employees to bring about result towards the goal." SM1.

"Strategic alignment is the process whereby a company has a clear vision and goals and cascades these through the levels of organisation as that harmony is achieved and everyone is moving towards the same direction."SM2.

"Looking at the overall business strategy and processes and linking these all together based on the business structure" SM3
Similarly, the survey data highlighted the concept of 'bringing togetherness' with participants frequently using various terms to define strategic alignment. These terms include 'link', 'align', 'merge', 'connect' and 'organize'. These terms are similar to terms used to define strategic alignment in extant literature (see for example [30]).

\subsection{Challenges, barriers and enablers}

Initially, survey participants were asked to identify three barriers regarding the strategic alignment of business and IT strategies. The challenges identified in this study are akin to [5] inhibitors. The authors defined inhibitors as organizational internal practices that affect the implementation and execution of a successful information technology alignment. The key themes that emerged are communication, corporate culture, lack of resources, lack of effective leadership, lack of effective training, unclear vision and goals, and lack of commitment.

Similarly, for the same question, the three interview participants identified inconsistent messages, resistance to change, cost, employee engagement, change and risk management, and evolving technology. These challenges are typical management challenges associated with any change initiative and suggest that business and IT strategic alignment would require change management skills, as also suggested by [12]. Table 2 below highlights some solutions to the challenges identified in our study data.

Next, survey participants were asked to identify three enabling factors to the strategic alignment of business and IT strategy. Key replies that emerged were: effective communication, leadership skills, people management, transparency, consistency, vision, and culture.

\subsection{The value of strategic alignment model (SAM)}

Additional data collected in this study was framed around the four domains of the Strategic Alignment Model (SAM) to understand the value and practicality of SAM. 
Table 2 Challenges and solutions of strategic alignment of business and IT strategies as noted in the empirical data of this study

\begin{tabular}{|c|c|}
\hline Challenges & Solutions \\
\hline $\begin{array}{l}\text { Unclear vision and } \\
\text { goals }\end{array}$ & There should be clarity and communication of vision, goals, and vision of all those involved in the strategic alignment \\
\hline Resistance to change & $\begin{array}{l}\text { Change should be seen as a positive and not a negative, and as an evolving implantation of what works or not within } \\
\text { the organization }\end{array}$ \\
\hline $\begin{array}{l}\text { Lack of effective } \\
\text { leadership }\end{array}$ & $\begin{array}{l}\text { Strategic alignment should be driven by senior management and supported by middle management to gain buying } \\
\text { from employees. It must be reviewed continuously to reset focus and ensure complete implementation }\end{array}$ \\
\hline Lack of commitment & $\begin{array}{l}\text { There is the need for commitment at the senior level, and the leader/manager should follow through with the change } \\
\text { for success }\end{array}$ \\
\hline Corporate culture & $\begin{array}{l}\text { The culture of an organization can reduce or contribute to its strategic capabilities to management change. Therefore, } \\
\text { leaders must ensure there are the right power and organizational structures, and the right beliefs, assumptions, and } \\
\text { controls in place }\end{array}$ \\
\hline Lacking communication & $\begin{array}{l}\text { There is a need for streamlined (top-down) communication channels to avoid information overload, and transparency } \\
\text { and consistency of messages }\end{array}$ \\
\hline $\begin{array}{l}\text { Cost and lacking } \\
\text { resources }\end{array}$ & $\begin{array}{l}\text { To ensure due diligence and compliance, leaders need to provide resources and leverage opportunities. There should } \\
\text { be a clear resourcing model organization that aligns with skills fitting in with the organizations' strategic aims }\end{array}$ \\
\hline Employee engagement & People can make the difference. Managers should encourage participation for smoother SA transition \\
\hline \multirow{2}{*}{$\begin{array}{l}\text { Change and risk } \\
\text { management }\end{array}$} & There is a need for effective project planning and buy-in from all employees \\
\hline & $\begin{array}{l}\text { Leaders or managers should be change facilitators, encourage engagement and foster the right culture. They should } \\
\text { ensure that there are the right strategies and resources for SA }\end{array}$ \\
\hline Emerging technologies & $\begin{array}{l}\text { While emerging technologies can pose a risk, it can also be an opportunity for organizations to innovate and be } \\
\text { creative, and learn from past events }\end{array}$ \\
\hline
\end{tabular}

\subsubsection{Business strategy}

All participants agreed that organizations of all sizes (large, medium, and small) could benefit from the strategic alignment of business and IT strategies. Interview participants noted that strategic alignment saves time and resources, enables organizations to achieve their best, and enables organizations to stay competitive. This understanding is not new and has been noted in the works of [18, 19].

The interview participants also noted that COVID-19 restrictions and physical restrictions to some business premises are accelerating the demands for strategic alignment to reduce cost and enable continuity of business operations, see also [22]. The participants noted that organization strategic alignment consists of understanding the organizational mission, vision, long-term strategy, and developing a set of goals and communicating those plans to stakeholders to achieve set business strategies.

\subsubsection{Information technology strategy}

Participants were asked to identify three ways information and communication technologies (ICT) can help an organization create new business opportunities. Key replies (see Fig. 4) which emerged were: Innovation and automation of processes; Improve processes and performance; Improvement in communication and awareness; new market and product opportunities due to connectivity; and storing and processing data. As noted in [22], other ways are data analytics for better decision-making, artificial intelligence, and blockchain technology.

Participants were asked what characteristics of ICT help organizations create strategic business opportunities. Key themes that emerged were: Real-time communication (visuals and speed); data capture, storage, and management; accessibility and a user-friendly interface.

\subsubsection{Business infrastructure}

Survey participants were asked to identify three crucial organizational practices (Fig. 5) that can lead to successful strategic alignment of business and IT strategy. Key themes that emerged were: Communication planning; People management; Risk and project management; Forecasting; Reporting and feedback; Budgeting; Culture; and Vision.

Finally, survey participants were asked to identify three crucial skills required for the effective strategic alignment of business and IT strategy. Key themes that emerged were: Communication and Leadership with 12 responses each; Negotiation skills (6 responses), and; Listening skills with 3 responses.

While SAM helps to identify key factors, skills, and resources needed for strategic alignment, this paper extends this understanding by shedding light on how these factors, skills, and resources interact to enable effective and 
successful strategic alignment of business and IT strategies, which is one of the strengths of this paper.

\section{Conclusion and recommendations}

Strategic alignment is a positive way of creating efficiencies and achieving targets for businesses of any size. While there is no one-fit-all approach, strategic alignment of business and IT strategy in the COVID-19 era is high on the agenda for managers due to Government restrictions and the emerging new normal.

This paper sought to explain the 'how' and processes involved in achieving IT and business strategic alignment. Within this, the study explored the value and practicality of SAM and senior management's role in strategic alignment of business and IT strategies. Moreover, it was found that strategic alignment involves a process aligning, linking, or connecting organizational goals, strategies, structures, resources and creating an enabling internal business culture to achieve a common strategic aim. SAM was valuable in highlighting important external and internal factors that enable the effective and successful strategic alignment of business and IT strategies. Our study extends this by explaining how these elements and variables interact to enable successful business and IT strategies. Linking business and IT strategies were identified to improve processes and performance, improve communication and awareness, and bring about a new market and product opportunities with better data handling.

The business infrastructure needed for a smooth alignment of business and IT strategies is effective communication, people management and planning. Risk and project management, effective budgeting and having the right culture and vision in place were also identified as essential business infrastructure. In terms of business skills, communication, effective leadership, negotiation skills, and listening skills were noted as crucial. In terms of IT infrastructure and skills, software, network, and hardware along with data analytical skills, digital skills and literacy, programming, coding, collaboration, and communication skills, were the most important factors.

Culture and deep core beliefs held by senior managers play a vital role in implementing strategic alignment. These beliefs affect their acceptance of revolutionary technologies for fear of failure that stems from their unfamiliarity with the new technologies. Considering that they make the final decisions, their understanding of alignment or lack thereof can make alignment successful or a failure. This further highlights the significance of the role senior management drive in an organization's alignment. Therefore, it is recommended that businesses ensure they have a good understanding of the value of strategic alignment of business and IT strategies.

Achieving success in the strategic alignment of business and IT strategies requires a clear understanding of the business mission or a long-term goal to determine what aspects need further harmonization. This would enable to reduce the duplication of efforts and to harmonize conflicting agendas, interests, and goals within organizations. Finally, the success of any strategic alignment requires commitment from senior leadership in terms of providing support and resources to enable the process of strategic alignment. Resources needed may include technical expertise, financial or relational resources, which can be utilized effectively with careful prioritization.

\section{References}

1. Ciborra CU (1997) De profundis? Deconstructing the concept of strategic alignment. Scand J Inf Syst 9(1): 2. Available at: https:// aisel.aisnet.org/sjis/vol9/iss 1/2

2. Kearns GS, Lederer AL (2000) The effect of strategic alignment on the use of IS-based resources for competitive advantage. J Strateg Inf Syst 9(4):265-293

3. Sarkis J, Cohen MJ, Dewick P, Schröder P (2020) A brave new world: lessons from the COVID-19 pandemic for transitioning to sustainable supply and production. Resour Conserv Recycl

4. Al Hudhaif A (2021) Project execution obstacles: a case of King Abdulaziz Airport in Saudi Arabia. Int j inf tecnol. https://doi.org/ 10.1007/s41870-020-00602-w

5. Zendehdel Nobari B, Azar A, Kazerooni M et al (2020) Revisiting enterprise resource planning (ERP) risk factors over the past two decades: defining parameters and providing comprehensive classification. Int J Inf Tecnol. https://doi.org/10.1007/s41870020-00502-z

6. Apostolopoulos C, Halikias G, Maroukian K, Tsaramirsis G (2014) Measuring change risk for organisational decision making through a hierarchical model process approach. In: Liu K, Gulliver SR, Li W, Yu C (eds) Service science and knowledge innovation. ICISO 2014. IFIP Advances in Information and Communication Technology, vol 426. Springer, Berlin, Heidelberg. https://doi.org/10.1007/978-3-642-55355-4_46

7. Yadav J, Saini AK, Yadav AK (2021) Designing conceptual model and statistical validation for government-citizen participation model in Indian context. Int $\mathrm{j}$ inf tecnol 13:637-645. https://doi.org/10.1007/s41870-020-00563-0

8. Yadav J, Saini AK, Yadav AK (2019) Analysing and securing the sustainability of e-Government projects from technical aspect using employees perspective approach. Int J Inf Tecnol. https:// doi.org/10.1007/s41870-019-00333-7

9. Maroukian K, Apostolopoulos C, Tsaramirsis G (2017) Extending model driven engineering aspects to business engineering domain: a model driven business engineering approach. Int $\mathrm{j}$ inf tecnol 9:49-57. https://doi.org/10.1007/s41870-017-0009-8

10. Yamin M (2019) Managing crowds with technology: cases of Hajj and Kumbh Mela. Int J Inf Tecnol 11:229-237. https://doi. org/10.1007/s41870-018-0266-1

11. Almutairi MM (2021) Role of Big Data in education in KSA. Int J Inf Tecnol 13:367-373. https://doi.org/10.1007/s41870-02000489-7 
12. Henderson JC, Venkatraman N (1993) Strategic alignment: Leveraging information technology for transforming organizations. IBM Syst J 32(1):4-16

13. Luftman, J., 2004. Assessing business-IT alignment maturity. In Strategies for information technology governance (pp. 99-128). Igi Global.

14. McKeen JD, Smith H (2003) Making IT happen; critical issues in IT management. Wiley, Chichester

15. Wilson A, Baptista JJ, Galliers R (2013) Performing strategy: aligning processes in strategic IT

16. Benbya H, McKelvey B (2006) Using coevolutionary and complexity theories to improve IS alignment: a multi-level approach. J Inf Technol 21(4):284-298

17. Velcu O (2010) Strategic alignment of ERP implementation stages: an empirical investigation. Inf Manag 47(3):158-166

18. Yayla AA, Hu Q (2009) The impact of IT-business strategic alignment on firm performance: the role of environmental uncertainty and business strategy

19. Tallon PP, Pinsonneault A (2011) Competing perspectives on the link between strategic information technology alignment and organizational agility: insights from a mediation model. MIS Quart 2:463-486

20. Teece DJ, Pisano G, Shuen A (1997) Dynamic capabilities and strategic management. Strateg Manag J 18(7):509-533

21. Banker RD, Hu N, Pavlou PA, Luftman J (2011) CIO reporting structure, strategic positioning, and firm performance. MIS Quart 2:487-504
22. Zhang M, Chen H, Lyytinen K, Li X (2019) A co-evolutionary perspective on business and IT alignment: A review and research agenda

23. Afandi W (2017) The impact of strategic IT-business alignment: evidence from Saudi private small and midsize enterprises. Int J Bus Soc Sci 8(10):48-63

24. Chan YE, Reich BH (2007) IT alignment: what have we learned? J Inf Technol 22(4):297-315

25. Hirschheim R, Sabherwal R (2001) Detours in the path toward strategic information systems alignment. Calif Manage Rev 44(1):87-108

26. Souza D, Mukherjee D (2004) Overcoming the challenges of aligning IT with business. Inf Strategy-Pennsauken 20(2):23-31

27. Daneshvar P, Ramesh HN (2010) Review of information technology effect on competitive advantage-strategic perspective. Int J Eng Sci Technol 2(11):6248-6256

28. Smaczny T (2001) Is an alignment between business and information technology the appropriate paradigm to manage IT in today's organisations? Manag Decis 2:2

29. Arafat MA (2007) Strategic alignment between IT and business strategy (Doctoral dissertation, University of Nottingham).

30. Luftman J (2015) Strategic alignment maturity. Handbook on business process management 2 . Springer, Berlin, pp 5-43 